\title{
A Novel Application of an Anthelmintic Mixture for Use against Gastrointestinal Parasites of Red Deer (Cervus elaphus)
}

\author{
P. L. Hughes \\ Taihape Veterinary Services, Kotare Street, Taihape 4720, New Zealand \\ Correspondence should be addressed to P. L. Hughes; prhughes@inspire.net.nz
}

Received 25 June 2017; Revised 28 January 2018; Accepted 4 February 2018; Published 5 March 2018

Academic Editor: D. S. Lindsay

Copyright (C) 2018 P. L. Hughes. This is an open access article distributed under the Creative Commons Attribution License, which permits unrestricted use, distribution, and reproduction in any medium, provided the original work is properly cited.

\begin{abstract}
A mixture of proprietary anthelmintics delivering $0.5 \mathrm{mg} / \mathrm{kg}$ moxidectin, $9.06 \mathrm{mg} / \mathrm{kg}$ oxfendazole, $15 \mathrm{mg} / \mathrm{kg}$ levamisole, and $0.08 \mathrm{mg} / \mathrm{kg}$ selenium on bodyweight basis per os to red deer is investigated. On a deer farm with a history of parasite problems, six weaner red deer were treated orally with a 50/50 mixture of Exodus Pour-On and Oxfen C Plus (Ex/Ox) at a dose rate of $1 \mathrm{ml} / 5 \mathrm{~kg}$ bodyweight. Six herd mates were untreated. Eleven days later abomasal worm counts for the untreated deer revealed an arithmetic mean burden of 2,566 Ostertagia-type worms and 300 Trichostrongylus axei. No worms were detected in the abomasa of the treated group. Six yearling red deer were treated with the Ex/Ox combination and sent 39 days later to a slaughter plant where tissue samples were collected for residue analysis. Moxidectin was the only anthelmintic compound to show residues and the concentrations measured were well below maximum residue limits. Laboratory analysis of the Ex/Ox product after six-week storage at ambient temperature indicated good physical and chemical stability. These investigations support the hypothesis that the Ex/Ox combination can be an effective and practical anthelmintic option for use in red deer against a background of widespread gastrointestinal parasite resistance to the registered alternatives.
\end{abstract}

\section{Introduction}

It has been widely recognised by farmers and veterinarians in the deer industry for a number of years that the efficacy of anthelmintics used has decreased especially against Ostertagia-type strongyles $[1,2]$. Moxidectin pour-on, which until recently was the most common anthelmintic used on deer farms [3], has become ineffective to the point where it is now recommended that its use be discontinued [4]. Deer farmers in the Taihape district are generally aware of this problem and have largely ceased using the macrocyclic lactone (ML) pour-ons despite their obvious convenience over both oral and injection methods of treatment.

Moxidectin, however, still offers a considerable advantage against lungworm Dictyocaulus eckerti in deer [5]. In the Taihape region there has been a noticeable increase in lungworm disease in weaner deer where abamectin or eprinomectin has been used instead of moxidectin even when used in combination products, for example, Matrix C (Merial Ancare, Auckland, NZ). There has not been a recorded case of reduced efficacy of moxidectin against lungworm in deer, so persistent activity would still be expected to be maintained for $35-42$ days against this parasite [5].

A combination product including moxidectin is therefore desirable. The pour-on formulations are not now helpful, leaving injectable and oral formulations as possible alternatives. There are studies comparing the efficacy and plasma pharmacologic profiles of these two alternatives in deer $[4,6,7]$. On balance it would appear that the injectable formulation has higher efficacy but comparisons do show variability. Furthermore the dose rates used are extrapolated from other farmed ruminants species and the oral dose rate for moxidectin has not been established for deer.

Oral formulations are preferred by farmers in the Taihape region because of the pain expressed by deer after repeated skin injections and some needle injuries. Furthermore anthelmintic treatment has traditionally been achieved with a single application and farmers tolerate a considerable cost premium to maintain that convenience. The challenge then was to provide a highly concentrated mixture of the three active compounds so that a practical oral dose volume was achieved. 
To achieve this goal a mixture of proprietary anthelmintics $(\mathrm{Ex} / \mathrm{Ox})$ was proposed. The concern of administering a pour-on formulation per os was tempered by the fact that manufacturers recognise that pour-on formulations can be and are ingested via licking the application site. Exodus Pour-On contains $5 \mathrm{mg} / \mathrm{ml}$ moxidectin suspended in a soya bean oil and benzyl alcohol base neither of which would be expected to be toxic at the dose rates proposed to mammals (Merial Ancare Exodus Pour-On Safety Data Sheet). The first animals to receive the $\mathrm{Ex} / \mathrm{Ox}$ combination treatment were the authors own deer (in mid 2013) and no ill effects were recorded. The dose administered was derived from aiming to at least double the quantities of the three active compounds in a practical volume, with $1 \mathrm{ml} / 5 \mathrm{~kg}$ bodyweight being commonly used for oral drenches. A combination of $0.5 \mathrm{mg} / \mathrm{kg}$ moxidectin, $9.06 \mathrm{mg} / \mathrm{kg}$ oxfendazole, $15 \mathrm{mg} / \mathrm{kg}$ levamisole $\mathrm{HCI}$, and $0.08 \mathrm{mg} / \mathrm{kg}$ selenium was administered. This dose provides moxidectin at 2.5 times the "standard dose rate" and oxfendazole, levamisole, and selenium at twice the "standard dose rate" based on their use in sheep and cattle. The quantity of selenium included in this combination while a potential cause of toxicity was considered but regarded as not critical as previous work has shown that young deer are not particularly sensitive to an increase in selenium administration [8]. The most toxic anthelmintic compound in this combination for ruminants is levamisole [9].

The purpose of this investigation was to provide clinical information on the Ex/Ox drench combination which is now in common use in the Taihape region. The data provided here may enable veterinarians to make a more informed decision should they prescribe this anthelmintic combination to their deer farmer clients. The observations relate specifically to the use of this mixture of commercial anthelmintics and are confined at this stage for use in red deer. Wapiti and wapiti hybrid deer have been shown to be more susceptible to G/I parasites [10] so care is required in making extrapolations with those breeds.

\section{Materials and Methods}

The anthelmintic combination comprised Exodus Pour-On (Merial NZ Ltd, Auckland, NZ) and Oxfen C Plus (Merial NZ Ltd, Auckland, NZ). Exodus Pour-On has a label claim of $5 \mathrm{mg} / \mathrm{mL}$ moxidectin in a benzyl alcohol/soya bean oil solution. Oxfen C Plus has a label claim of $90.6 \mathrm{mg} / \mathrm{mL}$ oxfendazole, $150 \mathrm{mg} / \mathrm{mL}$ levamisole, and $0.8 \mathrm{mg} / \mathrm{mL}$ selenium in an aqueous suspension/solution with approximately $12 \%$ w/v of stabilisers, emulsifiers, and suspending agents. Each anthelmintic was mixed in equal amounts in a $5 \mathrm{~L}$ measuring cylinder. The mixture was poured into a $5 \mathrm{~L}$ drench pack and shaken to form a thick viscous solution which could pass through a normal oral drench gun system.

There were three components to the clinical investigation into the use of this anthelmintic mixture in red deer.

2.1. Efficacy. A 730 hind breeding and finishing property with a parasite problem in deer had already used the Ex/Ox combination in their deer. Most deer farms in the Taihape region are in this category. Faecal worm egg counts (FEC) from a mob of weaner deer provided an indication as to whether a sufficient gastrointestinal (G/I) worm burden was established to warrant further treatment and were made by the modified McMaster method [11]. These deer had been drenched 3.5 months earlier using the Ex/Ox combination when still with their dams. Six weaner mixed sex red deer were weighed and treated. Six undrenched deer of similar weight provided an on-farm control group. A new drench gun was used to give dose to individual bodyweight. The drench gun had been calibrated by checking the volume administered with a syringe at the start and twice more during administration to ensure accuracy. The tag numbers, weights for both groups, and volume of Ex/Ox combination used on the treated deer are presented in Table 1.

Eleven days after drenching (27th June 2016) all 12 deer were tranquilised and humanely slaughtered on farm and post mortem examination of the viscera was carried out. The lungs were all thoroughly examined to detect lungworm. Livers, abomasa, and small intestines were individually identified and sent to Gribbles Palmerston North Laboratory. Worm counts were carried out on the individual abomasa and small intestinal samples which were recorded against the tag number. These worm counts were based on examinations of $1 \%$ aliquots of abomasal and small intestinal washings and the contents passed through a $250 \mu \mathrm{m}$ mesh sieve. This procedure has been shown to reliably detect all but the early 4 th stage larvae [12]. Species composition of worm genera was based on examination of the spicule morphology of 50 randomly selected male worms recovered from pooled samples made up of equal-sized aliquots from all animals in the control group.

The liver samples were individually analysed for selenium concentrations.

2.2. Residue. Six rising one-year-old mixed sex red deer were individually identified by tag number, weighed, and drenched with $23 \mathrm{ml}$ of the Ex/Ox combination on the 20/8/15. The average weight of the six deer was $99 \mathrm{~kg}$, range $87-115 \mathrm{~kg}$. The dose rate of $23 \mathrm{ml}$ was chosen because it represented the dose rate applicable to the heaviest animal which is an industry recommendation. These six deer were sent with a line of 40 undrenched herd mates to a deer slaughter plant (DSP) by the author. Full documentation for all the deer was provided to the DSP manager and veterinarian. The date of slaughter was 28/9/15, 39 days after treatment. The DSP veterinarian collected muscle, liver, kidney, and fat samples from the six treated deer and from two further deer from the undrenched cohorts. The six treatment carcasses were discarded. All 32 tissue samples were sent to RJ Hills Laboratories, Hamilton. At this laboratory the samples were homogenised to a pulp with dry ice. A subsample of the homogenised sample was extracted with a sodium carbonate solution and acetonitrile. Salt was added to the extracts and shaken to separate the acetonitrile from the aqueous phase. An aliquot of the acetonitrile extract was cleaned up by dispersive Solid Phase Extraction, diluted, and then analysed by liquid chromatography mass spectroscopy for fenbendazole, fenbendazole sulfone, levamisole, moxidectin, and oxfendazole. 
TABLE 1: Tag numbers and weights for weaner mixed sex red deer with the volume of Exodus Pour-On and Oxfen C Plus 50/50 mixture used per os for treated individuals.

\begin{tabular}{lcccc}
\hline & Untreated & & \multicolumn{2}{c}{ Treated } \\
Tag number & Weight $(\mathrm{kg})$ & Tag number & Weight $(\mathrm{kg})$ & Dose of mix $(\mathrm{ml})$ \\
\hline 322 & 39.5 & 305 & 35.0 & 7.0 \\
356 & 36.0 & 401 & 26.0 & 5.5 \\
535 & 27.5 & 474 & 38.0 & 7.5 \\
583 & 43.0 & 713 & 27.0 & 5.5 \\
712 & 34.0 & 755 & 45.0 & 9.0 \\
803 & 43.0 & 8944 & 46.5 & 9.5 \\
\hline Average weight & 37.2 & & 36.3 & \\
\hline
\end{tabular}

2.3. Stability. Samples of the Ex/Ox anthelmintic combination were made using newly made commercial products and stored in high-density polyethylene plastic containers both at room temperature and at $2-8^{\circ} \mathrm{C}$ for 6 weeks. After storage the samples were shaken vigorously as per normal farm practice and the appearance of the mixture and its density were evaluated and the moxidectin, oxfendazole, and levamisole $\mathrm{HCl}$ contents were measured. This was carried out at Labtec Scientific and Technical Services, an International Accreditation New Zealand accredited independent laboratory. Moxidectin, oxfendazole, and levamisole HCL were all extracted in acetonitrile and were separated by reverse phase high performance liquid chromatography. Detection was by ultraviolet light absorption at $242 \mathrm{~nm}$ for moxidectin and $210 \mathrm{~nm}$ for oxfendazole and levamisole HCL. Quantitation was by external standardisation.

\section{Results}

3.1. Efficacy. Arithmetic mean pretrial FEC of 280 strongyle eggs/g indicated parasites were present in the mob under investigation.

The abomasal worm counts for the treatment group and the untreated group are presented in Table 2.

No parasites were found in the small intestine of any of the untreated group and no signs of lungworm infection were found in any of the deer at post mortem. Speciation of the Ostertagia-types revealed that $90 \%$ were Spiculopteragia asymmetrica, 6\% Spiculopteragia spiculoptera, and 4\% Ostertagia leptospicularis.

Analytical results of selenium content in the livers are shown in Table 3.

3.2. Residue. Residue concentrations for all samples were below the default detection limit $(0.005 \mathrm{mg} / \mathrm{kg})$ for fenbendazole, fenbendazole sulfone, oxfendazole, and levamisole. Residues in all kidney and liver samples were below the default detection limit for moxidectin. The residue concentrations for moxidectin in fat and muscle are shown in Table 4.

3.3. Stability. The Ex/Ox mixture showed good physical and chemical stability over the 6-week storage period at both $2-8^{\circ} \mathrm{C}$ and room temperature. It maintained its appearance as a white suspension, with no change in density $(1.022 \mathrm{~g} / \mathrm{mL})$ over that time. Assay results after 6 weeks of storage showed
TABLE 2: Abomasal worm burdens from weaner mixed sex red deer individually identified into untreated and treated groups. The latter group was dosed per os with Exodus Pour-On Oxfen C Plus 50/50 mixture at $1 \mathrm{ml} / 5 \mathrm{~kg}$ bodyweight 11 days prior to slaughter.

\begin{tabular}{|c|c|c|c|}
\hline Tag number & Haemonchus & Ostertagia & T. axei \\
\hline \multicolumn{4}{|c|}{ Untreated group } \\
\hline 322 & 0 & 1100 & 500 \\
\hline 356 & 0 & 1900 & 700 \\
\hline 535 & 0 & 2200 & 100 \\
\hline 583 & 0 & 1200 & 100 \\
\hline 712 & 0 & 4800 & 100 \\
\hline 803 & 0 & 4200 & 30 \\
\hline $\mathrm{AM}$ & 0 & $2,566.7$ & 300 \\
\hline GM & 0 & $2,193.2$ & 217.5 \\
\hline \multicolumn{4}{|c|}{ Treated group } \\
\hline 305 & 0 & 0 & 0 \\
\hline 401 & 0 & 0 & 0 \\
\hline 474 & 0 & 0 & 0 \\
\hline 713 & 0 & 0 & 0 \\
\hline 755 & 0 & 0 & 0 \\
\hline 844 & 0 & 0 & 0 \\
\hline $\mathrm{AM}$ & 0 & 0 & 0 \\
\hline GM & 0 & 0 & 0 \\
\hline$\% \operatorname{Red} \mathrm{AM}$ & & $>99.9$ & $>99.9$ \\
\hline$\%$ Red GM & & $>99.9$ & $>99.9$ \\
\hline$P$ value ${ }^{*}$ & & 0.0000 & 0.0000 \\
\hline
\end{tabular}

$\%$ Red $\mathrm{AM}=$ percentage reduction of arithmetic mean; \%Red GM = percentage reduction of geometric mean. ${ }^{*}$ Compared to untreated based on ANOVA using log transformed (count +1 ) values.

concentrations of $2.7,45.5$, and $78.9 \mathrm{mg} / \mathrm{mL}$ for moxidectin, oxfendazole, and levamisole, respectively. Based on the label claims and $50 \%$ dilution of each product the expected assay concentrations would be $2.5,45.3$, and $75 \mathrm{mg} / \mathrm{mL}$, respectively.

\section{Discussion}

Elimination of abomasal parasites was achieved with the oral dose of $1 \mathrm{ml} / 5 \mathrm{~kg}$ bodyweight of the Ex/Ox combination, including a large burden of Ostertagia-type parasites 
TABLE 3: Liver selenium concentrations from weaner mixed sex red deer individually identified into untreated and treated groups. The latter group was dosed per os with Exodus Pour-On and Oxfen C Plus 50/50 mixture at $1 \mathrm{ml} / 5 \mathrm{~kg}$.

\begin{tabular}{|c|c|}
\hline Tag number & Liver selenium nmol/kg \\
\hline \multicolumn{2}{|c|}{ Untreated } \\
\hline 322 & 800 \\
\hline 356 & 580 \\
\hline 535 & 300 \\
\hline 583 & 570 \\
\hline 712 & 430 \\
\hline 803 & 330 \\
\hline Mean & 502 \\
\hline \multicolumn{2}{|c|}{ Treated } \\
\hline 305 & 1340 \\
\hline 401 & 2260 \\
\hline 474 & 1880 \\
\hline 713 & 2040 \\
\hline 755 & 2460 \\
\hline 844 & 2290 \\
\hline Mean & 2045 \\
\hline
\end{tabular}

(Adequate range $850-5000 \mathrm{nmol} / \mathrm{kg}$ ).

TABLE 4: Results from laboratory analysis of tissues taken from six rising one-year-old mixed sex red deer dosed per os with a 50/50 mixture of Exodus Pour-On and Oxfen C Plus at a minimum of $1 \mathrm{ml} / 5 \mathrm{~kg} 39$ days prior to slaughter and two rising one-year-old red deer that were controls.

\begin{tabular}{lccc}
\hline Deer \# & Group & \multicolumn{2}{c}{ Moxidectin $\mathrm{mg} / \mathrm{kg}$} \\
& & Fat & Muscle \\
\hline 1 & Treated & 0.07 & 0.008 \\
2 & Treated & 0.012 & $<0.005$ \\
3 & Treated & 0.022 & $<0.005$ \\
4 & Treated & $<0.005$ & $<0.005$ \\
5 & Treated & 0.044 & 0.006 \\
6 & Treated & 0.042 & $<0.005$ \\
7 & Control & 0.007 & $<0.005$ \\
8 & Control & $<0.005$ & $<0.005$ \\
\hline
\end{tabular}

with three different species represented. Investigations by Lawrence 2011, 2012, and 2013 have confirmed that Spiculopteragia asymmetrica, Spiculopteragia spiculoptera, and Ostertagia leptospicularis have become resistant to moxidectin pour-on treatment. All three species were represented in the worm burdens of the animals on the farm in Taihape where this investigation was conducted.

Spiculopteragia asymmetrica was the most common species identified on this farm. Interestingly in another study by Lawrence et al. [6], moxidectin at a dose rate of $0.2 \mathrm{mg} / \mathrm{kg}$ per os only achieved a $91.8 \%$ efficacy against this parasite. This study was on a Te Anau property that had recognised a poor clinical response to moxidectin pour-on, similar to that on the Taihape property. Greater than $99.9 \%$ efficacy was shown for this parasite in the Taihape case, which is encouraging and suggests that a $0.5 \mathrm{mg} / \mathrm{kg}$ dose rate of moxidectin orally may be more appropriate at least in this combination mixture.

The anthelmintic resistance status of the Taihape property is unknown but it has a similar history to many others in the Taihape district, namely, more than 20 years of regular moxidectin and abamectin pour-on use. Although there was no specific diagnosis of ML resistance, there was sufficient evidence and concern to move to the "off label" $\mathrm{Ex} / \mathrm{Ox}$ combination drench. Despite earlier work $[5,13]$ showing high efficacy for moxidectin pour-on, the observations of farmers and veterinarians in this district is that there are likely now very few deer farms where moxidectin pour-on is efficacious against the Ostertagia-type parasites.

A problem for veterinarians in the deer industry is that the faecal egg count reduction test (FECRT) is not as helpful as it is in sheep for example. Previous studies by Anderson and Wilson [14] have shown that there is a poor correlation between FEC and total worm burdens in deer. In addition, studies by Mackintosh et al. [7] have shown that the FECRT in deer overestimates the efficacy of anthelmintics and is therefore an unreliable diagnostic test. Hence the FECRT cannot be used to establish ML resistance status of a property and while we had collected faeces from farms using the Ex/Ox combination drench showing zero FEC 10-14 days after drenching this finding cannot be used to support high drench efficacy. This was the reason that the postslaughter investigation was undertaken on the farm in Taihape.

Selenium liver analysis was carried out to determine what the changes in concentrations were after dosing at $0.2 \mathrm{mg} / \mathrm{kg}$ sodium selenate. The concentrations were below the adequate range in the untreated group and above in the treated group. This was surprising because these weaner deer had been treated 3.5 months prior on their dams with the $\mathrm{Ex} / \mathrm{Ox}$ combination. This finding illustrates that selenium can be quite rapidly depleted in deer and on this property something in the order of 6 weekly dosing at the higher dose rate of $\mathrm{Ex} / \mathrm{Ox}$ could be required to maintain liver concentrations in the adequate range. It does need to be stated however that selenium responsive conditions in deer have been reported rarely [15]. Toxicity is the concern and while toxic reference ranges have not been published for deer, toxic concentrations in cattle livers have been above $80,000 \mathrm{nmol} / \mathrm{kg}$ [16]. It would seem highly unlikely that concentrations of that magnitude would be breached by using the Ex/Ox combination even if overdosing occurred (e.g., at double rates) and it was used monthly. The safety of the Ex/Ox combination is supported by its use in several thousand weaner deer over a four-year period. A six-week dosing interval for rising one-year-old deer from weaning until spring pasture flush (3-5 drenches total) appears to work well in many commercial situations.

Moxidectin was the only anthelmintic compound to show residues, an expected finding given the pharmacology of the three actives, and the WHP of 10 days for levamisole and benzimidazoles in deer. It was expected that levamisole and the benzimidazole would be metabolised within 35 days and that moxidectin would persist in low levels in fat (J Hurst 
pers. com.). Five of the 6 treated and one of the controls had moxidectin residues in fat. The highest was $0.070 \mathrm{mg} / \mathrm{kg}$ and mean was $0.033 \mathrm{mg} / \mathrm{kg}$. The Ministry of Primary Industry (MPI) published maximum residue limit (MRL) for moxidectin in fat of deer is $0.5 \mathrm{mg} / \mathrm{kg}$ [17]. The mean residue was $6.5 \%$ of the MRL. Two muscle samples had moxidectin residues detected, one at $0.008 \mathrm{mg} / \mathrm{kg}$ and one of $0.006 \mathrm{mg} / \mathrm{kg}$; all others were below the default detection limit. The MPI published MRL for moxidectin in muscle is $0.02 \mathrm{mg} / \mathrm{kg}$ [17].

A recent study did not achieve this residue result [18]. In that study a single aberrant levamisole residue exceeding the MRL was reported in fat from nine rising one-year-old wapiti hybrid deer. These deer had been treated with moxidectin injection $(0.2 \mathrm{mg} / \mathrm{kg})$ plus oral oxfendazole $(18.12 \mathrm{mg} / \mathrm{kg})$ and oral levamisole $(15 \mathrm{mg} / \mathrm{kg})$. This combination is a triple action drench recommended to farmers and veterinarians in the deer industry in an attempt to manage the widespread drench resistance [19]. This recommendation was further supported by three slaughter studies $[4,6,7]$. While the $\mathrm{Ex} / \mathrm{Ox}$ combination is an alternative it is possible that it may not be as effective in controlling resistant Ostertagia-type infections as the combination described above particularly in wapiti type deer. Efficacy is undoubtedly more important than WHP as in longer term the deer industry needs effective anthelmintics to succeed. More trial work is needed comparing efficacy of the Ex/Ox combination to the moxidectin injection $(0.2 \mathrm{mg} / \mathrm{kg})$ plus oral oxfendazole $(18.12 \mathrm{mg} / \mathrm{kg})$ and oral levamisole $(15 \mathrm{mg} / \mathrm{kg})$ recommended by Lawrence.

This residue investigation was not undertaken to make any claim about having the WHP recognised by the New Zealand Food Safety Authority. The data obtained from this clinical investigation only adds a small amount to the information that veterinarians have when prescribing the "off label" use of triple combination anthelmintics to their deer farmer clients. The reality is, though, that currently the only products registered for use in deer are known to be widely ineffective and by inference their continuing use is more rapidly selecting for further resistance. "Off label" anthelmintic recommendations are, therefore, essential for many deer farms in New Zealand.

The stability study showed that the Ex/Ox combination was stable for at least six weeks when stored at room temperature or $2-8^{\circ} \mathrm{C}$. The sample assay showed anthelmintic content above the expected concentration by $8,0.4$, and $5 \%$ for moxidectin, oxfendazole, and levamisole, respectively. This degree of variation is within the allowable tolerances for manufacturing overage and analytical variation for these types of products (J Hurst pers. com.).

In conclusion, a 50/50 mixture of Exodus Pour-On and Oxfen C Plus combination given orally at $1 \mathrm{ml} / 5 \mathrm{~kg}$ bodyweight to weaner red deer was effective against the Ostertagiatype parasites on a Taihape deer farm. A 39-day WHP has been shown to be adequate in a single clinical investigation and the mixture was stable for at least six weeks. The novel application of this anthelmintic mixture would appear to have practical application for the New Zealand deer industry, but its use is limited to veterinary prescription.

\section{Abbreviations}

DSP: Deer slaughter plant

Ex/Ox: Exodus Pour-On and Oxfen C Plus 50/50 mixture

FEC: Faecal worm egg count

FECRT: Faecal egg count reduction test

G/I: Gastrointestinal

ML: Macrocyclic lactone

MPI: Ministry of Primary Industries

MRL: Maximum residue limit

WHP: Withholding period (for meat).

\section{Disclosure}

Data in this manuscript has been presented at the society of Sheep and Beef Cattle Veterinarians of the New Zealand Veterinary Association 2017 conference and the New Zealand Society for Parasitology 2017 meeting.

\section{Conflicts of Interest}

The author declares that they have no conflicts of interest.

\section{Acknowledgments}

Hannah Chua, Justin Hurst, and Phil McKenna are acknowledged for their considerable help in collecting samples and analysing data and script. Merial Ancare provided some financial support for the laboratory costs.

\section{References}

[1] D. W. Lawrence, "Cervine Anthelmintics. The bubble has burst," in Proceedings of the Deer Branch NZVA, vol. 28, pp. 87-92, 2011.

[2] D. W. Lawrence, "Moxidectin drug residue trial," in Proceedings of the Deer Branch of NZVA, vol. 28, pp. 95-97, 2011.

[3] F. Castillo-Alcala, P. R. Wilson, W. E. Pomroy, and S. O. Hoskin, "A survey of anthelmintic use and internal parasite control in farmed deer in New Zealand," New Zealand Veterinary Journal, vol. 55, no. 2, pp. 87-93, 2006.

[4] D. W. Lawrence, J. T. MacGibbon, and P. C. Mason, "Moxidectin pharmacokinetics and resistance in deer," in Proceedings of the Deer Branch NZVA, vol. 29, pp. 41-45, 2012.

[5] C. G. Mackintosh, T. Quaeshi, R. E. Waldruph Labes, M. Taylor, A. Murphy, and P. Johnstone, "Persistance of moxidectin activity against nematodes in red deer," in Proceedings of the Proceedings of the deer branch of the NZVA, vol. 14, pp. 149-154, 1997.

[6] D. W. Lawrence, J. T. MacGibbon, and P. C. Mason, "Efficacy of levamisole, moxidectin oral, moxidectin injectable and monepantel against ostertagia-type nematodes in deer," in Proceedings of the NZVA conference, vol. 301, pp. 233-240, 2013.

[7] C. G. Mackintosh, C. Cowie, K. Fraser, P. Johnstone, and P. C. Mason, "Reduced efficacy of moxidectin and abamectin in young red deer (Cervus elaphus) after 20 years of moxidectin pour-on use on a New Zealand deer farm," Veterinary Parasitology, vol. 199, no. 1-2, pp. 81-92, 2014.

[8] C. G. Mackintosh, J. M. Gill, and K. Turner, "Selenium supplementation of young red deer (cervus elaphus)," New Zealand Veterinary Journal, vol. 37, no. 4, pp. 143-145, 1989.

[9] J. Vercruysse and E. Claerebout, "Safety of anthelmintics," MSD Veterinary Manual, vol. 11, p. 2255, 2016. 
[10] S. Parsons, C. G. Mackintosh, and D. A. Wharton, "A comparison of lungworm faecal larval counts and trichostrongyloid faecal egg counts between red deer (Cervus elaphus) and red deer $\times$ wapiti F1 hybrids," New Zealand Veterinary Journal, vol. 42, no. 3, pp. 110-113, 1993.

[11] H. V. Whitlock, "Some modifications of the McMaster helminth egg-counting technique and apparatus," Journal of the Council for Scientific and Industrial Research, vol. 21, pp. 177-180, 1948.

[12] P. B. McKenna, "Comparison of two worm counting procedures for the enumeration of abomasal and small intestinal nematode parasites of sheep," Veterinary Parasitology, vol. 157, no. 3-4, pp. 254-259, 2008.

[13] K. A. Waldrup, C. G. Mackintosh, M. S. Duffy et al., "The efficacy of a pour-on formulation of moxidectin in young red and wapiti-hybrid deer," New Zealand Veterinary Journal, vol. 46, no. 5, pp. 182-185, 1998.

[14] M. V. Anderson and P. R. Wilson, "Deer parasite studies," in Proceedings of the Proceedings of the Deer Branch of the NZVA, vol. 1, pp. 78-88, 1984.

[15] R. S. Ellison, “Trace elements in deer," in Proceedings of the Deer Branch of the NZVA, vol. 12, pp. 57-68, 1995.

[16] J. M. Gill, "Selenium poisoning in dairy cattle," New Zealand Veterinary Journal, vol. 41, no. 1, p. 46, 1993.

[17] A. Kinsella, "Food notice: Maximum Residue Levels for Agricultural Compounds," 2016, http://mpi.govt.nz/documentvault/11329.

[18] D. W. Lawrence, "Cervine triple combination anthelmintic residue study - moxidectin, oxfendazole and levamisole," in Proceedings of the Society of Sheep and Beef Veterinarians of the NZVA and Cervetec, pp. 181-188, 2015.

[19] D. W. Lawrence, "Deer anthelmintic residue trial," Vetscript, vol. 28, no. 3, pp. 32-34, 2015. 


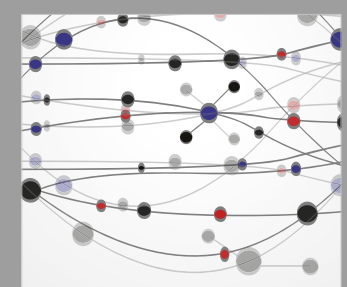

The Scientific World Journal
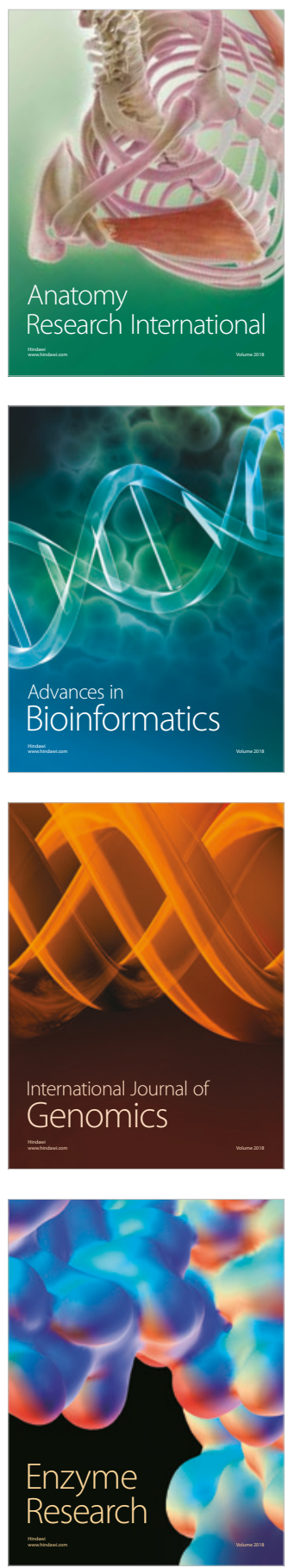
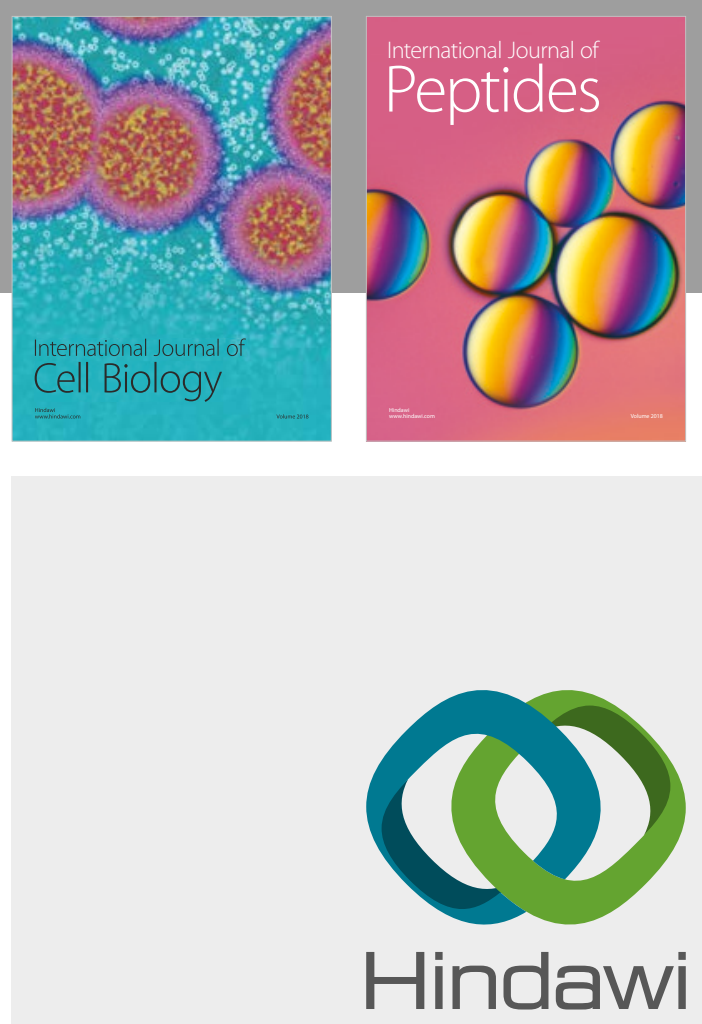

Submit your manuscripts at

www.hindawi.com
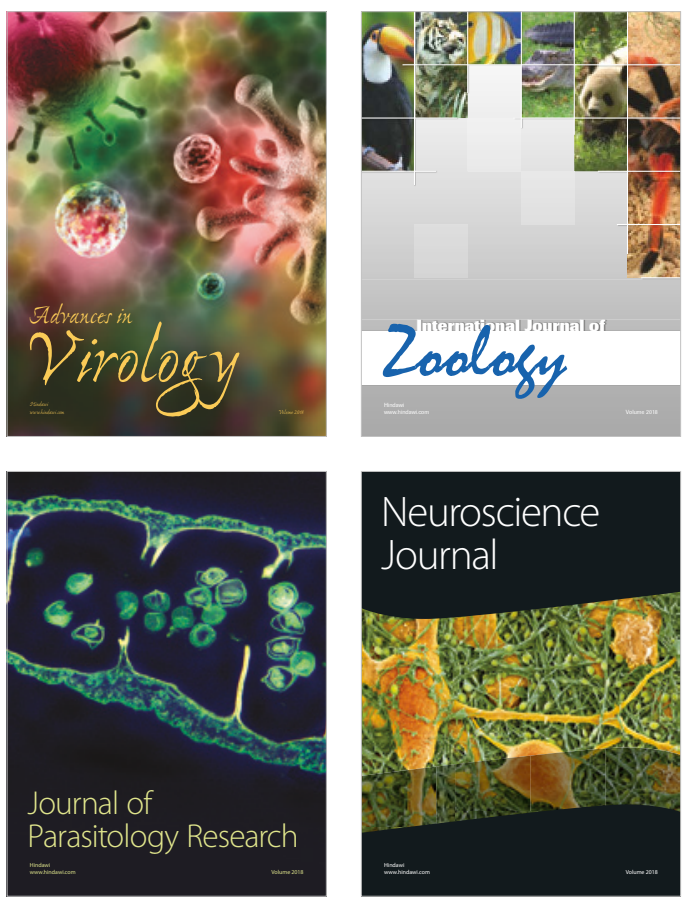
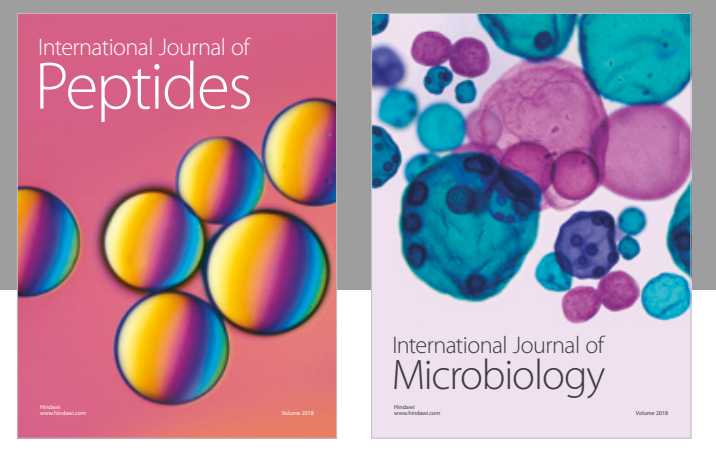

nternational Journal of Microbiology
Journal of
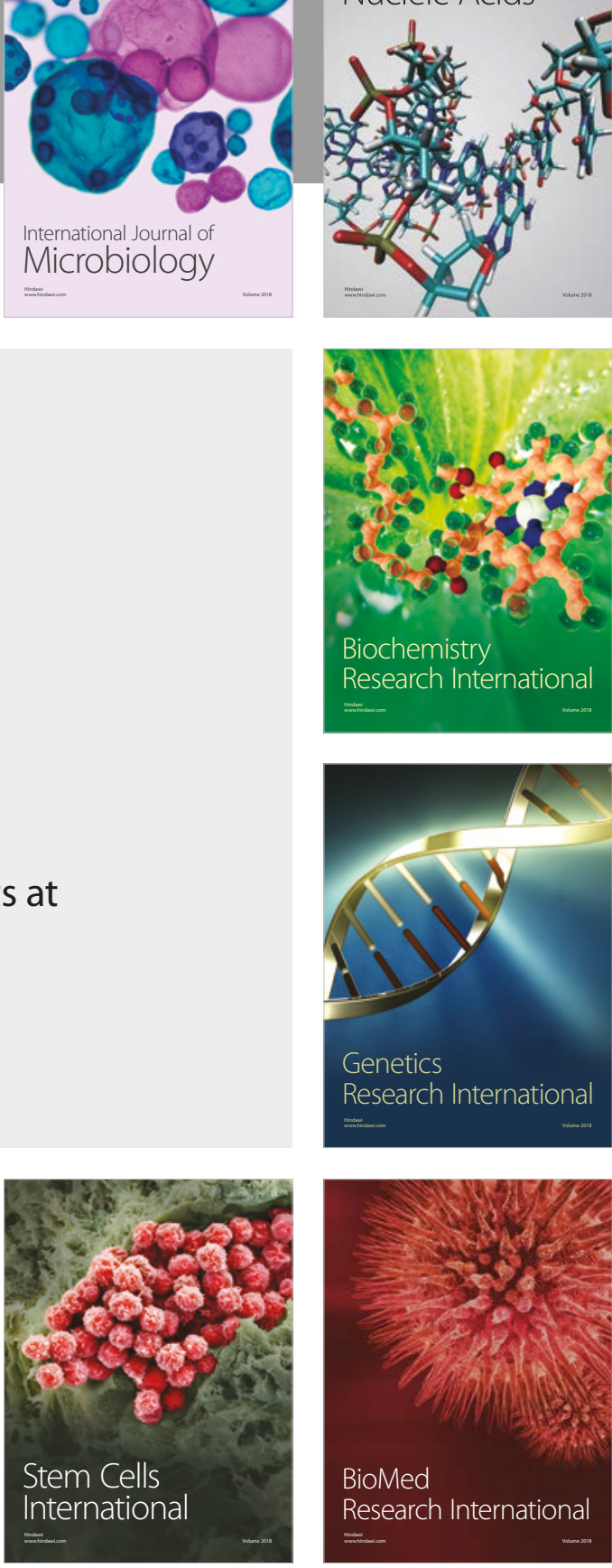
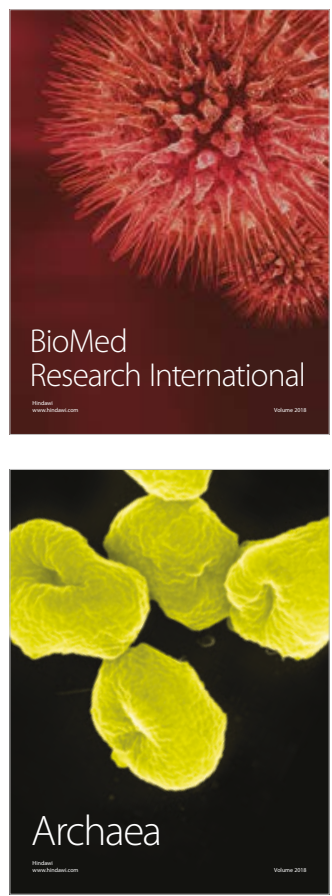